\title{
Lama Pengerjaan, Volume Anestetik Lokal, dan Angka Keberhasilan Blokade Aksilar dengan Panduan Pencitraan Ultrasonografi pada Prosedur Arterio-Venous Shunt
}

\author{
Ara Guntara, ${ }^{1}$ Dedi Fitri Yadi, ${ }^{2}$ Ruli Herman Sitanggang ${ }^{2}$ \\ ${ }^{1}$ Bagian Anestesiologi dan Terapi Intensif Rumah Sakit Paru Goenawan Cisarua Bogor, \\ ${ }^{2}$ Departemen Anestesiologi dan Terapi Intensif \\ Fakultas Kedokteran Universitas Padjadjaran/Rumah Sakit Dr. Hasan Sadikin Bandung
}

\begin{abstract}
Abstrak
Kunci keberhasilan melakukan blokade aksilar adalah mendistribusikan secara optimal anestetik lokal ke sekeliling saraf, hal ini tercapai dengan panduan pencitraan ultrasonografi. Penelitian ini bertujuan menilai lama pengerjaan, volume anestetik lokal, dan angka keberhasilan blokade aksilar dengan panduan pencitraan ultrasonografi. Metode penelitian adalah deskriptif prospektif. Penelitian dilakukan di Rumah Sakit Dr. Hasan Sadikin Bandung pada bulan Maret-April tahun 2014 terhadap 40 pasien (21-60 tahun), status fisik American Society of Anesthesilogist (ASA) II, menjalani pembedahan dalam blokade aksilar dengan panduan pencitraan ultrasonografi. Fungsi sensorik dan motorik dinilai setiap 5 menit selama 15 menit. Keberhasilan blokade dinilai dari hilangnya fungsi sensorik dan motorik pada saraf medialis, radialis, ulnaris, dan muskulokutaneus. Hasil penelitian didapatkan lama pengerjaan blokade aksilar rata-rata dengan panduan pencitraan ultrasonografi 548 detik (9,1 menit), volume anestetik lokal dibutuhkan $10 \mathrm{~mL}$ dan angka keberhasilan blokade aksilar sebesar 97,5\%. Penelitian lain lama pengerjaan dengan bantuan alat stimulasi saraf tepi selama 11,2 menit, volume total anestetik lokal dibutuhkan 30-40 mL, dan angka keberhasilan 60-85\%. Simpulan, panduan pencitraan ultrasonografi dapat mempersingkat pengerjaan, mengurangi volume obat anestesi lokal, dan meningkatkan keberhasilan blokade aksilar.
\end{abstract}

Kata kunci: Arterio-venous shunt, blokade aksilar, panduan ultrasonografi

\section{Procedure Time, Local Anaesthetic Volume, and Success Rate of Axillary Block with Ultrasound Guidance in Arterio-Venous Shunt Procedure}

\begin{abstract}
The key requirement for successful axillary block is to ensure optimal distribution of local anesthetic around the nerve structure. This goal is most effectively achieved under sonographic visualization. This study aimed to assess block procedure time, minimum volume of local anesthetic required, and success rate of axillary brachial plexus block under ultrasound guidance. This study was conducted between March and April 2014 in Dr. Hasan Sadikin General Hospital, Bandung. This was an observational prospective study involving 40 patients (21-60 years old) with American Society of Anesthesiologist (ASA) physical status II who underwent arterio-venous shunt under axillary brachial plexus block. Sensory and motor functions were assessed every five minutes for 15 minutes. A successful block was defined as complete sensoric and motoric loss in median, radial, ulnar, and musculocutaneus nerve distributions by 15 minutes. Results showed average block procedure time of 548 seconds $(9.1 \mathrm{~min})$, total volume of local anesthetic of $10 \mathrm{~mL}$, and block success rate of $97.5 \%$. This study concludes that ultrasound guidance can reduce block procedure time and required local anesthetic volume as well as improving the success rate of axillary brachial plexus block.
\end{abstract}

Key words: Arterio-venous shunt, axillary block, ultrasound guidance

Korespondensi: Ara Guntara, dr., SpAn, Bagian Anestesiologi dan Terapi Intensif Rumah Sakit Paru Goenawan Cisarua Bogor, Jl. Selakupi No. 41, Rt 02/03 Sindang Sari, Bogor 16118, Mobile 08122348838, Email araguntara@yahoo.com 


\section{Pendahuluan}

Blokade aksilar merupakan salah satu pilihan teknik anestesia yang dapat digunakan untuk pembedahan ekstremitas atas. Blokade aksilar adalah blokade saraf cabang terminal pleksus brakialis yang meliputi saraf medialis, radialis, ulnaris, dan juga muskulokutaneus. ${ }^{1,2}$ Indikasi blokade aksilar adalah untuk anestesia pada operasi di daerah lengan bawah, pergelangan tangan, dan tangan. Keuntungan klinis blokade aksilar dapat mengatasi nyeri dengan durasi lama, kejadian mual dan muntah rendah, serta perawatan di rumah sakit lebih singkat., ${ }^{3,4}$

Berdasarkan pada hasil penelitian tentang keberhasilan blokade aksilar menunjukkan angka kegagalan teknik blokade aksilar dengan menggunakan panduan stimulasi saraf perifer sebesar $14,5 \%$, sehingga dilakukan anestesia umum yang tidak direncanakan. Kelemahan blokade aksilar memakai panduan stimulasi saraf perifer adalah terjadi komplikasi seperti cedera saraf dan penyuntikan pada pembuluh darah. Pasien sering kali mengeluh parestesia ataupun rasa pegal di otot karena eksitasi yang ditimbulkan oleh alat stimulasi saraf perifer. Hal ini merupakan kekurangan blokade aksilar menggunakan alat stimulasi saraf perifer. ${ }^{4}$

Kunci kesuksesan teknik blokade saraf tepi adalah mendistribusikan obat anestesi lokal ke sekeliling struktur saraf secara optimal. Tujuan ini dapat tercapai secara efektif dengan panduan pencitraan ultrasonografi, sehingga struktur saraf tepi dapat dilihat secara akurat serta dapat melihat distribusi anestetik lokal di sekitar saraf. Penelitian tentang blokade aksilar menyatakan bahwa dengan pemakaian panduan ultrasonografi secara signifikan telah meningkatkan keberhasilan blokade saraf tepi, serta komplikasi seperti penusukan saraf atau suntikan intravaskular dapat diminimalisasi. ${ }^{5}$

Pemakaian ultrasonografi sebagai panduan pada blokade saraf tepi memberikan beberapa keuntungan, antara lain adalah mempercepat tindakan blokade saraf tepi, angka keberhasilan blokade tinggi, mengurangi volume anestetik lokal dan juga mempercepat onset blokade. Hal ini dikarenakan ultrasonografi memberikan pencitraan secara langsung terhadap struktur saraf sehingga penyuntikan obat anestesi lokal lebih akurat serta dapat mengurangi volume obat anestesi lokal. ${ }^{6}$

Pada penelitian sebelumnya, keberhasilan blokade aksilar dengan panduan pencitraan ultrasonografi adalah 95\%, lama pengerjaan 9-10 menit, dan volume anestetik lokal yang dibutuhkan $18 \mathrm{~mL}^{4,5}$

Blokade aksilar dapat dipergunakan untuk memfasilitasi operasi arterio-venous shunt (AV shunt). Operasi AV shunt merupakan tindakan anastomosis arteri dengan vena sebagai salah satu akses vaskular yang sering kali dikerjakan pada penderita end stage renal disease (ESRD). Pembedahan ini dilakukan di lengan bawah pada lengan yang tidak dominan. ${ }^{7}$ Penelitian ini bertujuan menilai lama pengerjaan, volume anestetik lokal yang dipakai, dan juga angka keberhasilan blokade aksiler dengan panduan ultrasonografi pada pasien yang menjalankan prosedur AV-shunt.

\section{Subjek dan Metode}

Penelitian ini adalah penelitian observasional deskriptif melalui pengambilan data dengan cross sectional prospektif terhadap 40 pasien menjalani prosedur AV shunt yang dilakukan tindakan anestesia blokade aksiler memakai panduan ultrasonografi di Central Operating Theatre lantai 4 Rumah Sakit Dr. Hasan Sadikin Bandung pada bulan Maret-April tahun 2014.

Kriteria inklusi pada penelitian ini adalah pasien yang menjalani pembedahan AV-shunt, status fisik American Society of Anesthetist (ASA) II dan rentang usia 20-60 tahun. Kriteria eksklusi adalah pasien yang tidak kooperatif, menolak dilakukan blokade aksilar, kelainan sensoris dan motorik pada ekstremitas yang akan dilakukan blokade aksilar, infeksi lokal di sekitar lokasi injeksi untuk blokade aksilar, riwayat hipersensitivitas serta kontraindikasi terhadap pemakaian obat anestesi lokal.

Setelah mendapat persetujuan dari Komite Etik Penelitian Kesehatan Fakultas Kedokteran Universitas Padjadjaran/Rumah Sakit Dr. Hasan Sadikin Bandung, diberikan penjelasan 
mengenai prosedur yang akan dijalani pasien pada saat pembuatan AV-shunt. Persetujuan pasien diperoleh dengan cara menandatangani surat persetujuan (informed consent).

Saat di ruang persiapan, pasien dibaringkan terlentang dan dipasang alat pantau tekanan darah, laju nadi, laju napas, saturasi oksigen, selanjutnya dipasang kateter intravena ukuran 20G pada tangan yang berlawanan dengan lokasi yang akan dilakukan blokade.

Posisi lengan atas pasien abduksi 90 derajat dengan sendi siku fleksi 90 derajat. Tindakan septik dan juga antiseptik dilakukan dengan menggunakan povidon iodin $10 \%$ dan alkohol $70 \%$ di sekitar area aksila yang akan disuntik. Identifikasi saraf medianus, ulnaris, radialis, serta muskulokutaneus dengan menggunakan ultrasonografi SonoSite M-Turbo ${ }^{\circledR}$ linear probe. Penyuntikan anestetik lokal sampai terbentuk gambaran donut sign di saraf medialis, ulnaris, radialis, dan juga muskulokutaneus. Prosedur blokade aksilar memakai panduan pencitraan ultrasonografi ini dilaksanakan oleh spesialis anestesiologi konsultan anestesia regional.

Penilaian motorik serta sensorik dilakukan oleh peneliti setiap 5 menit selama 15 menit. Penilaian sensorik dengan pinprick test untuk saraf radialis dilakukan di lateral metatarsal posterior, saraf medianus di ujung jari tengah, saraf ulnaris di daerah kelingking, sedangkan untuk saraf muskulokutaneus di radial lengan bawah. Derajat sensorik diukur dengan skala $2=$ sensasi normal, $1=$ terasa tebal, dan $0=$ tidak terasa.

Penilaian fungsi motorik saraf medianus dilakukan dengan pergerakan ibu jari, saraf ulnaris dengan cara fleksi jari kelingking serta abduksi-adduksi jari tengah, saraf radialis dengan ekstensi pergelangan tangan dan siku, sedangkan saraf muskulokutaneus dengan cara fleksi lengan bawah. Penilaian motorik dengan skala $2=$ pergerakan serta kekuatan normal, $1=$ lebih lemah dari normal, dan $0=$ tidak ada pergerakan. Penghitungan dilakukan terhadap lama pengerjaan, volume anestetik lokal, dan penilaian keberhasilan blokade aksilar. Hasil penelitian ini dibandingkan dengan penelitian lain yang pernah dilakukan sebelumnya.

\section{Hasil}

Penelitian ini dilakukan pada 40 pasien yang menjalani prosedur AV-shunt yang dilakukan anestesia blokade aksilar memakai panduan ultrasonografi, terdiri atas laki-laki sebanyak 20 pasien $(50 \%)$ dan perempuan 20 pasien (50\%).

Usia terbanyak adalah 60 tahun sebanyak 7 subjek. Usia rata-rata seluruh sampel 48,37 tahun dengan usia minimum adalah 21 tahun dan maksimum 60 tahun. Berat badan subjek penelitian sebagian besar $50 \mathrm{~kg}$, yaitu 9 subjek. Berat badan rata-rata 51,67 kg dengan berat badan terbesar $65 \mathrm{~kg}$ dan terkecil $40 \mathrm{~kg}$.

Pencatatan lama pengerjaan blokade aksilar memakai panduan pencitraan ultrasonografi pada pembedahan AV-shunt dilakukan setiap pengerjaan blokade aksilar yang dilaksanakan oleh spesialis anestesiologi yang sama.

Waktu rata-rata pengerjaan blokade aksilar dengan panduan pencitraan ultrasonografi ialah 548 detik (9,1 menit), waktu terlama 616 detik (10,2 menit), serta tersingkat 451 detik (7,5 menit).

Jumlah lidokain 2\% yang digunakan pada blokade aksilar dengan panduan pencitraan ultrasonografi pada prosedur AV-shunt pada saraf muskulokutaneus sebanyak $2 \mathrm{~mL}$, saraf radialis $2 \mathrm{~mL}$, saraf medialis sebanyak $2 \mathrm{~mL}$, dan saraf ulnaris sebanyak $4 \mathrm{~mL}$.

Jumlah blokade aksilar yang berhasil adalah 39 subjek. Angka keberhasilan blokade aksilar dengan panduan pencitraan ultrasonografi adalah $98 \%$.

\section{Pembahasan}

Ultrasonografi ialah alat bantu yang relatif baru dalam anestesia regional. Hal ini merupakan investasi waktu dan biaya untuk pengadaan alat dan pelatihan untuk keterampilan penggunaan ultrasonografi. Pemakaian ultrasonografi pada anestesia regional yang dipergunakan seharihari memerlukan keterampilan khusus, oleh karena itu ahli anestesia harus meningkatkan kemampuan dalam penggunaan ultrasonografi dan harus memahami anatomi saraf tepi serta 
kemampuan untuk memahami gambaran pada pencitraan ultrasonografi. ${ }^{4}$

Kunci keberhasilan melakukan anestesia regional terutama pada blokade saraf tepi ialah memastikan obat anestesia lokal terdistribusi merata di sekeliling serabut saraf. Kondisi ini mudah tercapai dengan bantuan pencitraan ultrasonografi untuk mengidentifikasi saraf dan juga penyebaran anestetik lokal. Beberapa penelitian telah membuktikan bahwa panduan pencitraan ultrasonografi pada saat blokade saraf tepi meningkatkan angka keberhasilan, mempersingkat lama pengerjaan blokade, dan mengurangi volume obat anestesi lokal secara bermakna. ${ }^{5,6,8}$

Penelitian initelah mengobservasi sebanyak 40 subjek yang dilakukan prosedur arteriovenous shunt dengan anestesia blokade aksilar memakai panduan pencitraan ultrasonografi. Rentang berat badan subjek penelitian ini dari $40 \mathrm{~kg}$ sampai $65 \mathrm{~kg}$. Sebagian besar dengan berat badan $50 \mathrm{~kg}$. Temuan berat badan pada penelitian ini ialah bahwa pada pasien dengan ESRD cenderung berada di bawah nilai normal sehingga harus dipikirkan dosis toksik obat anestesia lokal yang dipergunakan. Pemberian obat dengan dosis minimal harus dilakukan pada pasien dengan ESRD.

Waktu yang dibutuhkan untuk pengerjaan blokade aksilar rata-rata adalah 548 detik $(9,1$ menit). Jika dibandingkan dengan penelitian lain, lama pengerjaan prosedur blokade aksilar rata-rata dengan panduan ultrasonografi ialah selama 9,3 menit, dibandingkan dengan dengan menggunakan bantuan alat stimulasi saraf tepi ialah selama 11,2 menit. ${ }^{4} \mathrm{Hal}$ ini membuktikan bahwa penggunaan pencitraan ultrasonografi sebagai panduan dalam mengerjakan blokade aksilar dapat mempersingkat lama pengerjaan prosedur tersebut. Lama pengerjaan blokade aksilar mempergunakan panduan pencitraan ultrasonografi dipengaruhi oleh keterampilan ahli anestesi dalam penggunaan ultrasonografi dan pemahaman terhadap anatomi saraf tepi.

Penelitian ini memperkuat hasil penelitian sebelumnya. Penyuntikan jumlah obat anestesi lokal dinyatakan cukup bila terjadi gambaran doughnut sign di sekeliling saraf yang dituju. Temuan pada penelitian ini, jumlah anestetik lokal, yaitu lidokain 2\% yang dibutuhkan pada tiap-tiap saraf, yaitu saraf muskulokutaneus sebanyak $2 \mathrm{~mL}$, saraf medialis sebanyak $2 \mathrm{~mL}$, saraf radialis sebanyak $2 \mathrm{~mL}$, dan saraf ulnaris sebanyak $4 \mathrm{~mL}$. Pada hasil penelitian terdahulu penggunaan obat anestesi lokal tiap saraf ratarata sebanyak $2-4 \mathrm{~mL}$.

Hasil penelitian sebelumnya menyatakan bahwa penggunaan anestetik lokal terutama pada blokade aksilar dengan mempergunakan panduan alat stimulasi saraf tepi atau teknik transarterial membutuhkan volume sekitar 30-40 mL, sedangkan pada hasil penelitian ini, blokade aksilar dengan panduan pencitraan ultrasonografi hanya membutuhkan anestetik lokal sebanyak 10-12 mL.6.9 Hal ini dikarenakan panduan pencitraan ultrasonografi membantu untuk mengidentifikasi tiap-tiap saraf, melihat penempatan jarum dan penyebaran anestetik lokal di sekitar saraf secara tepat, sehingga dengan jumlah minimal anestetik lokal dapat meliputi seluruh serabut saraf yang dituju sehingga terjadi blokade saraf yang diinginkan. Hal ini juga meningkatkan angka keberhasilan blokade aksilar apabila dibandingkan dengan blokadeaksilardenganmemakaitekniklainnya. Blokade aksilar dengan bantuan alat stimulasi saraf tepi atau teknik transarterial, tidak dapat melihat secara langsung penempatan jarum serta penyebaran obat anestesia lokal seperti pada penggunaan pencitraan ultrasonografi, sehingga dibutuhkan obat anestesi lokal dalam jumlah besar yang diharapkan dapat meliputi serabut saraf secara keseluruhan.

Blokade sensorik dan juga motorik berhasil pada 39 subjek saat pemeriksaan menit ke15. Kegagalan blokade sensorik serta motorik pada saraf ulnaris ditemukan di menit ke-15 sebanyak 1 (satu) subjek. Angka keberhasilan blokade aksilar pada penelitian ini mencapai 97,5\%. Pada penelitian lain, angka keberhasilan blokade aksilar dengan panduan pencitraan ultrasonografi berkisar 80\% sampai 95\%. ${ }^{4-6,9}$

Pada penelitian lain yang membandingkan blokade aksilar memakai panduan pencitraan ultrasonografi dengan alat stimulasi saraf tepi, menyatakan bahwa angka keberhasilan dengan bantuan alat stimulasi saraf tepi ialah berkisar $60 \%$ sampai $85 \%{ }^{4,5}$ Kunci keberhasilan dalam 
melakukan tindakan blokade saraf tepi adalah memastikan anestetik lokal terdistribusi secara optimal di sekitar serabut saraf. Hal ini dapat tercapai memakai pencitraan ultrasonografi, yang telah terbukti dari berbagai penelitian sebelumnya bahwa pencitraan ultrasonografi meningkatkan angka keberhasilan blokade saraf tepi, serta dapat menghindari kejadian penyuntikan intraneural dan intravaskular. ${ }^{5}$

Pada penelitian ini didapatkan kegagalan pada 1 subjek yang kemungkinan disebabkan teknik pengerjaan blokade aksilar yang tidak sempurna. Penggunaan panduan pencitraan ultrasonografi tidak menjamin keberhasilan blokade akan mencapai angka $100 \%$.

Hasil penelitian ini memperkuat penelitian sebelumnya yang menyatakan bahwa panduan pencitraan ultrasonografi membuat tindakan blokade aksilar dapat lebih cepat, kebutuhan volume anestetik lokal yang lebih sedikit, serta angka keberhasilan lebih tinggi dibandingkan dengan tindakan blokade aksilar menggunakan panduan stimulasi saraf tepi.

\section{Simpulan}

Penggunaan pencitraan ultrasonografi pada blokade aksilar mempercepat lama pengerjaan blokade, mengurangi volume anestetik lokal, dan meningkatkan angka keberhasilan.

\section{Daftar Pustaka}

1. Ahtsham UN, Nidhi H, Arun GP, Chan VWS. Ultrasound-guided regional anesthesia performance in the early learning period. Reg Anesth Pain Med. 2012;37:51-4.

2. O'Donnell B, Riordan J, Ahmad I, Iohom G. A clinical evaluation of block characteristics using one mililiter $2 \%$ lidocaine in ultrasound-guided axillary brachial plexus block. Anasth Analg. 2010;111:808-10.

3. Bloc S, Mercadal L, Garnier L, Komly B. Comfort of the patient during axillary block placement: a randomized comparison of the neurostimulation and the ultrasound guidance techniques. Eur J Anaesth. 2010;27:628-33.

4. Chan VWS, Perlas A, McCartney CJL. Ultrasound guidence improves success rate of axillary brachial plexus block. Can J Anesth. 2007;54:165-70.

5. Marhofer P, Greher M, Kapral S. Ultrasound guidance in regional anaesthesia. $\mathrm{Br} \mathrm{J}$ Anaesth. 2005;94:7-17.

6. Harper GK, Stafford MA, Hill DA. Minimum volume of local anaesthetic required to surround each of the constituent nerves of the axillary brachial plexus, using ultrasound guidance. Br J Anaesth. 2010;104:633-6.

7. Yuwono HS. Ilmu bedah vaskuler-sains dan pengalaman praktis. Edisi ke-1. Bandung: Refika Aditama; 2010.

8. O'Donnell BD, Iohom G. An estimation of the minimum effective anesthetic volume of $2 \%$ lidocaine in ultrasoundguided axillary brachial plexus block. Anesthesiology. 2009;111:25-9.

9. Fredrickson M J, Ting FS, Chinchanwala S, Boland MR. Concomitant infraclavicular plus distal median, radial, and ulnar nerve blockade accelerates upper extremity anaesthesia and improves block consistency compared with infraclavicular block alone. Br J Anaesth. 2011;107(2):236 -42 . 